\title{
Trombocitopenia asociada al virus de la Hepatitis A: Reporte de 3 casos
}

Thrombocytopenia associated to the Hepatitis A virus: report of 3 cases

\author{
Rosa Ambulay ${ }^{1, a}$, Maria Gallosa ${ }^{2, b}$
}

\section{RESUMEN}

La trombocitopenia asociada al virus de la hepatitis A es un cuadro clínico poco frecuente. Esta asociación se caracteriza por tener dos formas de presentación: aislada o acompañada de síntomas sistémicos, siendo un signo en común la presencia de hepatitis. La alteración del sistema inmunológico, demostrado por la presencia de anticuerpos, sería la principal etiología. Se presentan tres casos, dos de ellos con síntomas sistémicos y uno con clínica aislada.

PALABRAS CLAVE: Hepatitis A, trombocitopenia, transaminasas. (Fuente: DeCS BIREME).

\section{SUMMARY}

The thrombocytopenia associated to the Hepatitis A virus is a rare clinical case. According to published cases, this association is characterized by two forms of presentation: isolated or accompanied by systemic symptoms, a common sign being the presence of hepatitis. The alteration of the immune system, demonstrated by the presence of antibodies, would be the main etiology of this pathology. Three cases are presented, two of them with systemic symptoms and one with isolated clinical symptoms.

KEYWORDS: Hepatitis A, thrombocytopenia, transaminases. (Source: MeSH NLM).

\section{INTRODUCCIÓN}

El virus de la hepatitis A, se caracteriza por presentar un cuadro clínico asintomático, anictérico o ictérico (1). En forma menos frecuente, se ha descrito manifestaciones hepáticas (bifásicas, colestásicas e insuficiencia hepática fulminante) y extrahepáticas (derrame pleural, insuficiencia renal y trombocitopenia) (2).

La fisiopatología de la trombocitopenia asociada al virus de la hepatitis A es de origen autoinmune o secundario a un síndrome hemofagocítico (3). Esta asociación es un fenómeno excepcional, motivo por el cual se decidió reportar tres casos del Hospital Regional Cayetano Heredia, Piura para así poder reconocer la trombocitopenia no sólo como una complicación extrahepática del virus de la hepatitis A, sino como un signo de severidad.

\section{PRESENTACIÓN DE LOS CASOS}

\section{Caso 1}

Varón de 4 años de edad, inició su enfermedad 9 días antes de su ingreso con fiebre y malestar general, cinco días después se añadió epistaxis, y dos días antes presentó petequias y coluria. Al examen físico: FR 26 x', FC 90 x', ictericia en escleras, petequias y equimosis en piel y mucosas, hígado a $3 \mathrm{~cm}$ debajo del reborde costal y bazo palpable de $2 \mathrm{~cm}$.

Hospital Cayetano Heredia. Departamento de Pediatría. Piura, Perú.

Hospital de Sullana. Unidad de Cuidados Intensivos de Neonatología. Piura, Perú.

Médico Asistente;

Jefe de la Unidad 
Los exámenes de laboratorio mostraron: Leucocitos $4470(\mathrm{~L} 49 \%) \times \mathrm{mm}^{3}$, plaquetas $6000 \times \mathrm{mm}^{3}$, hemoglobina 12,6 gr/dl, TGO 1329 UI/l, TGP 1557 $\mathrm{UI} / 1$, bilirrubina total $4,39 \mathrm{mg} / \mathrm{dl}$ (directa 3,58), TTP: 34", INR 1,06, albúmina 4,2 gr/dl, IgM para hepatitis A positivo. Se inició metilprednisolona a $1 \mathrm{mg} / \mathrm{k} /$ dosis y continuó con prednisona $1 \mathrm{mg} / \mathrm{k} /$ día. A las 48 horas de iniciado el tratamiento el recuento de plaquetas fue $20000 \times \mathrm{mm}^{3}$ y se observaron macroplaquetas en la lámina periférica. Fue dado de alta al cuarto día de su hospitalización.

\section{Caso 2}

Varón de un año de edad, con tiempo de enfermedad de un día caracterizado por gingivorragia, epistaxis y hematomas en los miembros inferiores y en el dorso. El día de su ingreso se añadió hematemesis. $\mathrm{Al}$ examen físico: FR 30 x', FC 100 x', equimosis perioral, hematomas y petequias distribuidos en brazos y piernas, y hepatomegalia. Los exámenes de laboratorio mostraron: leucocitos $4700 \mathrm{x} \mathrm{mm}^{3}$ (L $62 \%$ ), plaquetas $15000 \times \mathrm{xm}^{3}$, hemoglobina $9,6 \mathrm{gr} / \mathrm{dl}$, TGO 1694 UI/1, TGP 1313 UI/l, TP: 12”, INR 1,01, albúmina 4,45 gr/dl, IgM para Hepatitis A positivo.
Se inició metilprednisolona $15 \mathrm{mg} / \mathrm{k} /$ dosis única. $\mathrm{Al}$ quinto día de hospitalización el recuento de plaquetas fue $243000 \mathrm{x} \mathrm{mm}^{3}$, motivo por el cual se decidió su alta.

\section{Caso 3}

Mujer de 11 años de edad, iniciósu enfermedad 6 días antes de su ingreso con fiebre, malestar general, artralgias y cefalea, al día siguiente se añadiódolor abdominal tipo cólico por lo que acudió a la emergencia donde luego de atenderla, le dan de alta con diagnóstico de dengue probable sin signos de alarma, cuatro días antes la fiebre cedió, pero persistió el dolor abdominal de intensidad 6/10 asociado a diarrea. Dos días antes el dolor abdominal se tornó de gran intensidad y se agregó gingivorragia, lo que motivó su hospitalización. Al examen físico se encontró: FR 18 x', FC 80 x', sin lesiones en piel, hepatomegalia y dolor abdominal en el cuadrante superior derecho. Los exámenes de laboratorio mostraron: leucocitos $3900 \mathrm{x} \mathrm{mm}^{3}$ (L 63\%), plaquetas $142000 \mathrm{x} \mathrm{mm}^{3}$, hemoglobina $15 \mathrm{gr} / \mathrm{dl}$, TGO $1049 \mathrm{UI} / \mathrm{l}$, TGP 1105 UI/1. Se diagnosticó dengue con signos de alarma, recibiendo sintomáticos e hidratación endovenosa.

Tabla 1. Características clínicas y de laboratorio.

\begin{tabular}{|c|c|c|c|}
\hline & Caso 1 & Caso 2 & Caso 3 \\
\hline Edad & 4 años & 1 año & 11 años \\
\hline Sexo & Varón & Varón & Mujer \\
\hline Forma clínica de presentación & $\begin{array}{l}\text { Síntomas sistémicos, } \\
\text { Fiebre }\end{array}$ & $\begin{array}{l}\text { Trombocitopenia } \\
\text { aislada }\end{array}$ & $\begin{array}{l}\text { Síntomas sistémicos, } \\
\text { Fiebre/Astenia, } \\
\text { Cefalea/Artralgias }\end{array}$ \\
\hline Ictericia & Sí & No & $\mathrm{Si}$ \\
\hline Hepatomegalia & Sí & Sí & \\
\hline Esplenomegalia & Sí & No & Sí \\
\hline Hemoglobina (gr/dl) & 12,6 & 9,6 & 14,3 \\
\hline \multicolumn{4}{|l|}{ Hemograma } \\
\hline Leucocitos (cel/mm³) & 4470 & 4700 & 2590 \\
\hline Linfocitos $\left(\mathrm{cel} / \mathrm{mm}^{3}\right)$ & 2190 & 2914 & 1062 \\
\hline Plaquetas (cel/mm³) & 6000 & 15000 & 90000 \\
\hline Hepatitis & hipertransaminemia & hipertransaminemia & hipertransaminemia \\
\hline Bilirrubina & aumentadas & normales & aumentadas \\
\hline Anticuerpos antinucleares & NR & NR & NR \\
\hline Aspirado de médula ósea & NR & NR & NR \\
\hline Tratamiento & Metilprednisolona & Metilprednisolona & Sintomáticos \\
\hline
\end{tabular}


Tras 48 horas de hospitalización cursa con ictericia en escleras, plaquetas $90000 \mathrm{x} \mathrm{mm}^{3}$ y bilirrubina total $3,48 \mathrm{mg} / \mathrm{dl}(\mathrm{D} 3,41)$; la serología IgM para hepatitis A fue positiva. Los exámenes de dengue (IgM, IgG, NSI) fueron negativos. Al quinto día de enfermedad con un recuento de plaquetas en $248000 \mathrm{x} \mathrm{mm}^{3}$, se decidió su alta.

En la tabla 1 se muestran las características clínicas y de laboratorio mas relevantes de los tres casos.

\section{DISCUSIÓN}

La descripción de trombocitopenia inducida por virus es relativamente frecuente para Epstein Barr virus, citomegalovirus, varicela, dengue, sarampión, VIH, (4) - sobre todo en sus fases tardías-; en contraste, la trombocitopenia como signo extrahepático del virus de la hepatitis A, es una forma clínica poco frecuente.

Desde la publicación del primer caso realizada en 1982 se han documentado 21 casos, de los cuales 12 (57\%) casos pertenecen al área de pediatría, siendo su distribución según grupo etario: menores de 4 años, dos pacientes; de 5 a 10 años, seis pacientes y de 11 a 14 años, cuatro pacientes. La relación varón/mujer es $1,6 / 1(5)$.

Se han descrito dos formas de presentación: trombocitopenia aislada (6-8) y trombocitopenia asociada a síntomas sistémicos $(9,10)$. La trombocitopenia aislada, tiene un cuadro clínico similar a la trombocitopenia autoinmune, caracterizado por plaquetopenia severa o sangrado de mucosas. La forma sistémica se asocia frecuentemente a fiebre más síntomas digestivos (dolor abdominal, náuseas y vómitos) o síntomas inespecíficos (anorexia, astenia, cefalea). Ambos cuadros pueden cursar con ictericia con o sin visceromegalia, por lo que frecuentemente se encuentra en los exámenes auxiliares, aumento de las transaminasas y de la bilirrubina a predominio directo. Clásicamente el hemograma descrito en los casos de trombocitopenia asociado al virus de la hepatitis A, presenta leucopenia a predominio de los linfocitos.

De los casos de este reporte se puede observar que uno de ellos presentó una trombocitopenia aislada y los otros dos cursaron con síntomas digestivos o sistémicos, siendo la fiebre y la astenia, los más predominantes. Una característica en común, es que los tres casos presentaron hepatomegalia, asociada a incremento de las transaminasas; sólo dos de ellos cursaron con ictericia.

En cuanto a la fisiopatología, se esgrimen dos hipótesis, un fenómeno inmunológico y un síndrome hemofagocítico. La presencia de anticuerpos plaquetarios o de otros anticuerpos: anticitoplásmico, anticardiolipina, antifosfolipídicos, asociado a los hallazgos en el aspirado de médula ósea de megacariocitos hiperplásicos e inmaduros, sustentan el origen autoinmune $(11,12)$. Asimismo, la esplenomegalia y el daño endotelial favorecerían la destrucción periférica de las plaquetas. Por este motivo, la mayoría de pacientes reciben terapia inmunomoduladora (inmunoglobulina o corticoides sistémicos), observándose una respuesta terapéutica satisfactoria, hecho que refrenda la hipótesis inmunológica.

A ninguno de nuestros tres pacientes se le realizó dosaje sérico de anticuerpos antiplaquetarios ni aspirado de médula ósea. Sólo uno de ellos presentó en la lámina periférica macroplaquetas. Excepto el último caso, donde la sospecha inicial fue dengue con signos de alarma, los otros dos recibieron metilprednisolona. Cabe señalar que el paciente que no recibió terapia inmunomoduladora, presentó elevación del recuento de plaquetas en forma espontánea.

La importancia de la trombocitopenia asociada al virus de la hepatitis $\mathrm{A}$, está documentada en un estudio de análisis multivariado, en donde se concluye que la plaquetopenia es un signo de severidad, incluso más específico que el recuento total de leucocitos y que la proteína $\mathrm{C}$ reactiva (13). Ninguno de nuestros pacientes presentó inestabilidad hemodinámica ni evolución desfavorable.

\section{Contribución de autoría:}

RA: Obtención de la información de cada caso; RA, MG: Resumen de los casos y discusión; revisión y sugerencia de la presentación.

\section{Correspondencia:}

Rosa Ambulay Grados

Hospital Cayetano Heredia.

Av. Independencia $\mathrm{s} / \mathrm{n}$,

Urbanización Miraflores.

Castilla, Piura, Perú

Correo electrónico: yizzna@gmail.com 


\section{REFERENCIAS BIBLIOGRÁFICAS}

1. Corretger JM, Cruz M, Gonzalez-Hachero J. Infectología Pediátrica: Bases Diagnósticas y tratamiento. Ciudad de México: Editorial Amolca; 2001.

2. Rodriguez M, Haznedaroglu S, Yende S, Willner I. Hepatitis A: A potentially serious disease. Ann Intern Med.1998; 129(6): 506-507.

3. Hernández M, Martínez M, Valcárcel I, Marín L, Alfayate S. Hepatitis A. An uncommon associated pathology. Allergol Immunopathol (Madr). 2010; 38(5):285-287.

4. Montenegro-MedinaY,Rey-CaroL, Niederbacher J, Martínez-Vega R, Díaz-Quijano F, Villar-Centeno L. Papel de los anticuerpos antiplaquetarios en la infección viral: una revisión sistemática de la literatura. Biomédica. 2011; 31:35-43.

5. Jose W, Kumar K, Unnikrishnan A, Palaniappan M, Nair A, Pavithran K. Autoimmune thrombocytopenic purpura in acute hepatitis $\mathrm{A}-\mathrm{a}$ report and review of literature. Asia Pac J Oncol Hematol. 2010; 2:137-137.

6. Gönül T, Cumhur A, Nilden T, Özge K, Nefle Y. Immune thrombocytopenic purpura as sole manifestation in a case of acute hepatitis A. Turk $\mathrm{J}$ Gastroenterol. 2005; 16 (4):217-219.

7. Leblebisatan G, Tümgör G, Saşmaz I, Ozgür $\mathrm{O}$, Antmen B. Hepatitis A-associated immune hrombocytopenia. Turk J Gastroenterol. 2012; 23(2):195-197.
8. Rathika S, Sajitha N, Nutan K. Thrombocytopenia in Hepatitis A: An Atypical Presentation. Journal of Tropical Pediatrics.2004;50(4):241-242.

9. Niederbacher J, Monturiol X, Holguín E. Purpura trombocitopénica asociada a hepatitis A en niños. Salud UIS. 2006; 38:204-208.

10. Venkataravanamma P, Rau AT. Severe thrombocytopenia in association with hepatitsA. Indian Pediatrics. 2004; 41: 1178-1179.

11. Campos J, Hissae R, Tsukasa S, et al. Thrombocytopenia: diagnosis with flow cytometry and antiplatelet antibodies. Einstein. 2011; 9(2 Pt 1):130-4.

12. González X, Notario M. Alteraciones de la hemostasia en las enfermedades virales. Rev Cubana Hematol Inmunol Hemoter. 1999;15(1): 21-4.

13. Kim HS, Kim HS, Lee JY, et al. Initial thrombocytopenia as a simple, valuable predictor for clinical manifestation in acute hepatitis A. Scand J Gastroenterol. 2008; 43(1): 81-8.
Recibido: 19/09/2017

Aceptado: 20/03/2018 